University of Nebraska - Lincoln

DigitalCommons@University of Nebraska - Lincoln

Other Publications in Zoonotics and Wildlife

Disease

Wildlife Disease and Zoonotics

December 2006

\title{
Transfusion-associated transmission of West Nile virus, United States 2003 through 2005
}

\author{
Susan P. Montgomery \\ Jennifer A. Brown \\ Matthew Kuehnert \\ Theresa L. Smith \\ Nicholas Crall \\ See next page for additional authors
}

Follow this and additional works at: https://digitalcommons.unl.edu/zoonoticspub

Part of the Veterinary Infectious Diseases Commons

\begin{abstract}
Montgomery, Susan P.; Brown, Jennifer A.; Kuehnert, Matthew; Smith, Theresa L.; Crall, Nicholas; Lanciotti, Robert S.; Macedo de Oliveira, Alexandre; Boo, Thomas; Marfin, Anthony A.; and Transmission Investigation Team, 2003 West Nile Virus Transfusion-Associated, "Transfusion-associated transmission of West Nile virus, United States 2003 through 2005" (2006). Other Publications in Zoonotics and Wildlife Disease. 39.

https://digitalcommons.unl.edu/zoonoticspub/39
\end{abstract}

This Article is brought to you for free and open access by the Wildlife Disease and Zoonotics at DigitalCommons@University of Nebraska - Lincoln. It has been accepted for inclusion in Other Publications in Zoonotics and Wildlife Disease by an authorized administrator of DigitalCommons@University of Nebraska - Lincoln. 


\section{Authors}

Susan P. Montgomery, Jennifer A. Brown, Matthew Kuehnert, Theresa L. Smith, Nicholas Crall, Robert S. Lanciotti, Alexandre Macedo de Oliveira, Thomas Boo, Anthony A. Marfin, and 2003 West Nile Virus Transfusion-Associated Transmission Investigation Team 


\title{
Transfusion-associated transmission of West Nile virus, United States 2003 through 2005
}

\author{
Susan P. Montgomery, Jennifer A. Brown, Matthew Kuehnert, Theresa L. Smith, Nicholas Crall, \\ Robert S. Lanciotti, Alexandre Macedo de Oliveira, Thomas Boo, Anthony A. Marfin, and the 2003 West \\ Nile Virus Transfusion-Associated Transmission Investigation Team
}

BACKGROUND: National blood donation screening for West Nile virus (WNV) started in June 2003, after the documentation of WNV transfusion-associated transmission (TAT) in 2002.

STUDY DESIGN AND METHODS: Blood donations were screened with investigational nucleic acid amplification assays in minipool formats. Blood collection agencies (BCAs) reported screening results to state and local public health authorities. Donor test results and demographic information were forwarded to CDC via ArboNET, the national electronic arbovirus surveillance system. State health departments and BCAs also reported suspect WNV TATs to CDC, which investigated these reports to confirm WNV infection in blood transfusion recipients in the absence of likely mosquito exposure.

RESULTS: During 2003 to 2005, a total of 1,425 presumptive viremic donors were reported to CDC from 41 states. Of 36 investigations of suspected WNV TAT in 2003, 6 cases were documented. Estimated viremia levels were available for donations implicated in four TAT cases; the median estimated viremia was 0.1 plaqueforming units (PFUs) per $\mathrm{mL}$ (range, 0.06-0.50 PFU/mL; 1 PFU equals approximately 400 copies $/ \mathrm{mL}$ ).

CONCLUSIONS: National blood screening for WNV identified and removed more than 1,400 potentially infectious blood donations in 2003 through 2005. Despite the success of screening in 2003, some residual WNV TAT risk remained due to donations containing very low levels of virus. Screening algorithms employing selected individual-donation testing were designed to address this residual risk and were fully implemented in 2004 and 2005. Continued vigilance for TAT will evaluate the effectiveness of these strategies.
W est Nile virus (WNV) is a flavivirus maintained in an enzootic cycle of mosquito transmission among birds; humans are incidental hosts. The strain of WNV currently circulating in North America can cause a spectrum of illness in infected humans. Based on estimates derived from serosurveys, ${ }^{1,2}$ approximately 20 percent of infections cause an acute febrile illness; less than 1 percent result in serious neuroinvasive disease, including encephalitis, meningitis, and acute flaccid paralysis. Nearly 80 percent of infected people remain asymptomatic and many develop viremia without discernible illness, raising blood safety concerns. ${ }^{3,4}$ Based on an estimated 140 infections for every case of neuroinvasive disease, ${ }^{1,2}$ as many as 800,000 human WNV infections occurred in the United

ABBREVIATIONS: BCA(s) = blood collection agency(-ies); $\mathrm{CSF}=$ cerebrospinal fluid; IDT = individual-donation testing; $\mathrm{MP}(\mathrm{s})=\operatorname{minipool}(\mathrm{s}) ; \operatorname{PFU}(\mathrm{s})=$ plaque-forming unit(s); PVD $(\mathrm{s})=$ presumptive viremic donor(s); rtPCR = real-time quantitative reverse transcriptase polymerase chain reaction; TAT = transfusion-associated transmission; WNF = West Nile fever; WNND = West Nile neuroinvasive disease(s); WNV = West Nile virus.

From the Division of Vector-Borne Infectious Diseases, Centers for Disease Control and Prevention, Fort Collins, Colorado; the Division of Viral and Rickettsial Diseases, CDC, Atlanta, Georgia; the Nebraska Health and Human Services System, Lincoln, Nebraska; State Branch, Epidemiology Program Office, CDC, Atlanta, Georgia; and the Global AIDS Program, CDC, Nairobi, Kenya.

Address reprint requests to: Susan P. Montgomery, DVM, MPH, Parasitic Diseases Branch/DPD/NCID/CDC, 4770 Buford Highway, Atlanta, GA 30341; e-mail: SMontgomery@cdc.gov. Received for publication May 5, 2006; revision received May 5, 2006, and accepted August 16, 2006.

doi: 10.1111/j.1537-2995.2006.01030.x

TRANSFUSION 2006;46:2038-2046. 
States during 2002 and 2003 when 5812 cases of neuroinvasive disease were reported. ${ }^{5,6}$

In 2002, WNV became the first vector-borne flavivirus found to be transmitted through blood transfusion; 23 cases of WNV transfusion-associated transmission (TAT) were documented in persons transfused with blood components from 16 viremic donors. ${ }^{7,8}$ In response to this new risk to blood safety, US and Canadian blood collection agencies (BCAs) deferred donors with fever and headache, symptoms suggestive of WNV-related illness, during the week before donation and blood screening assays were implemented during the $2003 \mathrm{WNV}$ epidemic season.

As part of public health surveillance for WNV, CDC, state, and local public health officials began collecting reports of suspected TAT in 2002. In addition, BCAs initiated retrospective testing of archived individual-donation samples in selected areas and traced reactive donations forward to identify possible TATs. Starting in June 2003, nucleic acid amplification tests (NATs) were used to identify and remove potentially infectious components collected from asymptomatic donors. In this report, we present the results of blood donor surveillance and describe the results of investigations of reported WNVTAT cases since 2002.

\section{MATERIALS AND METHODS}

\section{Blood donor screening}

In June 2003, two commercial WNV screening NATs were distributed under investigational new drug approval by FDA, produced by Manufacturer A and Manufacturer B. The Manufacturer A assay was performed with minipools (MPs) of 6 donation samples and real-time quantitative reverse transcriptase polymerase chain reaction (rtPCR), whereas the Manufacturer B assay used MPs of 16 donation samples and transcription-mediated amplification method. ${ }^{9-11}$

Reactive MPs were defined with manufacturerspecified parameters and cutoffs in pooled testing. ${ }^{12,13}$ The component donations of reactive MPs were individually tested with the same manufacturer-specific testing modality as the MP test (rtPCR for Manufacturer A and transcription-mediated amplification for Manufacturer B). For both assays, a reactive donation was defined as a donation from a reactive MP that was also reactive on individual-donation testing (IDT). Donors were presumed to be WNV viremic if their donation tested reactive twice by IDT (presumptive viremic donors [PVDs]), which was shown to have 99 percent positive predictive value for true WNV infection..$^{10}$ One large BCA, screening donations with Manufacturer B assays, considered a single IDT result with a signal to cutoff ratio value above 20 to define the donor as a PVD; this was shown to have greater than 95 percent correlation with confirmed positive results at that BCA.
BCAs contacted viremic donors to inform them of their test results and to collect additional information, including recent travel history, other exposure history, and review of symptoms compatible with WNV illness occurring within 3 weeks before or after donation. Both manufacturers performed additional testing to confirm the presence of $\mathrm{WNV}$ in the donation sample and determine the viral titer. Infection by WNV was confirmed by detection of virus-specific immunoglobulin M (IgM) antibody in the donation or seroconversion documented in followup samples with WNV-specific IgM antibody enzymelinked immunosorbent assay (ELISA) testing.

To assist with national WNV surveillance and control efforts, BCAs were asked to share WNV NAT screening data by reporting PVDs to the donor's state of residence health department. In addition to the date of donation and preliminary testing results, PVD age, sex, zip code, and the results of follow-up antibody testing were reported. State health departments also performed separate epidemiologic investigations of reported WNV infections in PVDs.

State health departments were asked to report PVDs to ArboNET, a cooperative surveillance project between CDC and 57 state and local health departments that monitors domestic arbovirus activities. PVDs were reported as asymptomatic infections; if a PVD developed WNV illness, the state reported that illness to ArboNET according to the corresponding clinical category (e.g., West Nile fever [WNF] or West Nile neuroinvasive diseases [WNNDs] including encephalitis, meningitis, meningoencephalitis, or acute flaccid paralysis).

\section{WNV TAT investigations}

To determine the effectiveness of blood screening and to identify blood donors with very-low-level viremia that may not have been detected with MP NAT, suspected WNV TAT cases were investigated. Cases were identified in two ways: 1) public health investigations of WNV illness among blood donors and transfusion recipients (public health-initiated investigations) and 2) forward tracing of cases identified by BCAs performing retrospective IDT of archived samples in selected areas (BCA-initiated investigations).

\section{Public health-initiated investigations}

During routine investigation of WNV illnesses, public health authorities inquired whether reported patients had either received a blood transfusion or donated blood during the 30 days before illness onset. If the patient had received blood, his or her illness was considered a suspected WNV TAT case; if the patient had donated blood, the recipients of the associated blood components were considered suspected WNV TAT case-patients. Suspected cases were reported to CDC and investigated. 


\section{BCA-initiated investigations}

To evaluate the sensitivity of the MP-NAT screening algorithm, several BCAs in regions with high levels of WNV transmission retested archived individual-donation samples that had previously tested nonreactive in MPs. Detection of reactive donations triggered immediate quarantine and retrieval to prevent transfusion of corresponding components. Because the donations did not react in MPNAT screening, however, some components had already been transfused before these results were obtained. Additional WNV RNA and WNV-specific IgM antibody testing of the available index donation specimens and follow-up donor samples was conducted to confirm WNV infection. Transfusion recipients of the potentially infectious blood components were notified of the WNV testing results. The BCA notified CDC when any implicated components had been transfused and an investigation was initiated.

\section{Transfusion recipient investigations}

For both public health- and BCA-initiated investigations, the suspected case-patient's attending physician was contacted and a medical record review was performed with a standard data collection form. Information on WNV illness diagnosis, medical history, donation or transfusion record, clinical course, and outcome was recorded. When available, specimens collected before or at the time of transfusion and follow-up serum samples were submitted for WNV-specific antibody and virus testing at CDC's Arboviral Disease Branch (Fort Collins, CO).

\section{Definitions}

A viremic component was defined as any component derived from a donation that contained WNV RNA based on NAT performed by the BCA or CDC. WNV infection in a donor was confirmed by the presence of WNV-specific antibody either in the index donation or in subsequently collected follow-up samples.

A probable case of WNV TAT was defined as a recipient of a viremic component who then developed evidence of WNV infection, defined as identification of WNVspecific antibody in the recipient's samples (serum or cerebrospinal fluid [CSF]) collected after transfusion with the implicated component. A confirmed case was a probable case that also satisfied one of the following: 1) the recipient did not have exposure to possibly infectious mosquitoes within 14 days before illness onset, 2) stored recipient samples collected before and after transfusion demonstrated that the infection was temporally related to the implicated transfusion, or 3) a recipient of a cocomponent from the same blood donation developed a confirmed or probable WNV infection.

\section{RESULTS}

\section{PVDs reported to ArboNET}

During 2003, a total of 818 PVDs were reported to ArboNET by 33 states; 640 (78\%) were from 6 states: Colorado, Kansas, Nebraska, North Dakota, South Dakota, and Texas (Fig. 1, Table 1). These states accounted for 55 percent of the WNND cases reported to ArboNET in 2003. Dates of PVD donation ranged from May 21 to December 1, 2003; the peak number of PVDs donated blood during the week

\section{Laboratory testing}

$\mathrm{BCA}$ retrospective testing samples and followup samples were forwarded to CDC for further evaluation. Available blood components that had not been transfused were recalled and tested by rtPCR for presence of virus genome. When sufficient volumes were available, plasma components were tested for WNV RNA with a modification of a previously published protocol in which a larger input sample volume was utilized for testing to increase sensitivity. ${ }^{3}$ RNA was extracted from $0.5 \mathrm{~mL}$ of plasma with a kit (Qiagen, Valencia, CA) and resuspended in $0.1 \mathrm{~mL}$. This amplification was performed as previously described, with the exception that $25 \mu \mathrm{l}$ of RNA was included in the amplification mixture. In addition, all samples were tested for WNV-specific antibody by IgM-capture ELISA; antibody specificity for WNV was confirmed by plaque reduction neutralization testing at $\mathrm{CDC}{ }^{14}$

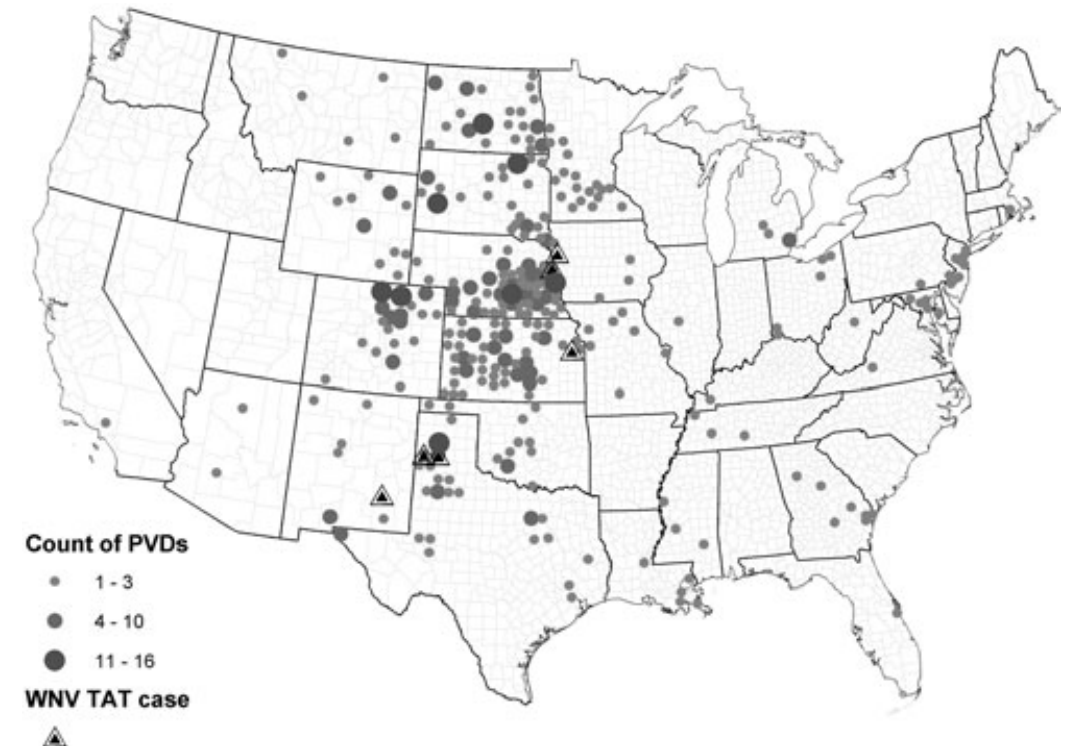

Fig. 1. Number of reported WNV PVDs and confirmed and probable TAT cases by county of recipient residence, 2003. 


\begin{tabular}{|c|c|c|c|}
\hline \multirow[b]{2}{*}{ State† } & \multicolumn{3}{|c|}{ PVDs by year } \\
\hline & 2003 & 2004 & 2005 \\
\hline$\overline{\mathrm{AL}}$ & 0 & 0 & 4 \\
\hline$A Z$ & 3 & 36 & 20 \\
\hline CA & 1 & 66 & 88 \\
\hline $\mathrm{CO}$ & 83 & 24 & 2 \\
\hline $\mathrm{DE}$ & 0 & 1 & 0 \\
\hline $\mathrm{FL}$ & 1 & 3 & 1 \\
\hline $\mathrm{GA}$ & 9 & 4 & 4 \\
\hline ID & 0 & 0 & 1 \\
\hline $\mathrm{IL}$ & 1 & 1 & 12 \\
\hline IN & 0 & 1 & 7 \\
\hline IA & 5 & 4 & 18 \\
\hline KS & 101 & 4 & 30 \\
\hline $\mathrm{KY}$ & 2 & 1 & 1 \\
\hline LA & 5 & 12 & 21 \\
\hline MD & 9 & 1 & 2 \\
\hline MA & 1 & 0 & 0 \\
\hline $\mathrm{MI}$ & 6 & 3 & 6 \\
\hline $\mathrm{MN}$ & 23 & 2 & 11 \\
\hline MS & 4 & 2 & 2 \\
\hline MO & 7 & 2 & 1 \\
\hline MT & 5 & 0 & 2 \\
\hline $\mathrm{NE}$ & 182 & 3 & 49 \\
\hline NV & 0 & 5 & 3 \\
\hline $\mathrm{NJ}$ & 8 & 1 & 0 \\
\hline NM & 10 & 15 & 5 \\
\hline NY & 2 & 1 & 1 \\
\hline NC & 0 & 0 & 1 \\
\hline ND & 62 & 1 & 5 \\
\hline $\mathrm{OH}$ & 4 & 0 & 16 \\
\hline OK & 20 & 8 & 16 \\
\hline $\mathrm{OR}$ & 0 & 1 & 1 \\
\hline PA & 2 & 1 & 4 \\
\hline SD & 63 & 3 & 18 \\
\hline TN & 3 & 0 & 0 \\
\hline $\mathrm{TX}$ & 66 & 16 & 57 \\
\hline UT & 0 & 0 & 4 \\
\hline VA & 1 & 0 & 0 \\
\hline WI & 0 & 2 & 4 \\
\hline WV & 1 & 0 & 0 \\
\hline WY & 21 & 0 & 0 \\
\hline Total & 711 & 224 & 417 \\
\hline \multicolumn{4}{|c|}{$\begin{array}{l}\text { These counts reflect PVD reports to ArboNET for public } \\
\text { release. Additional reports have been included in the } \\
\text { description of the PVDs but are not listed here. } \\
\text { † AK, AR, CT, HI, ME, NH, RI, SC, VT, and WA reported no PVDs } \\
\text { during } 2003 \text { through } 2005 \text {. }\end{array}$} \\
\hline
\end{tabular}

ending August 23 (Fig. 2). Complete demographic information was available for 811 PVDs; 446 (56\%) were male and the median age was 46 years (range, $15-83$ years). Of these $811,6(0.7 \%)$ developed WNND (median age, 45 years; range, 28-76 years) and 137 (17\%) developed WNF (median age, 46 years; range, 17-76 years).

A total of 224 PVDs were reported to CDC in 2004 from 29 states. Most PVDs (169 PVDs, 75\%) were reported from 5 states (Arizona, California, Colorado, Louisiana, and New Mexico; Fig. 3, Table 1), the same 5 states where 58 percent (663 cases) of $1,148 \mathrm{WNND}$ cases were reported in 2004. Dates of donation by PVDs ranged from April 23 to October 26, 2004, with a peak number reported during the week ending July 31 (Fig. 2). Complete demographic information was available for 220 PVDs; 127 (58\%) were male and the median age was 50 years (range, 1783 years). Of these 220, 4 (1.8\%) developed WNND (ages $35,65,69$, and 77 years) and $66(30 \%)$ developed WNF (median age, 52 years; range 17-75 years).

In 2005 (Fig. 4, Table 1), 417 PVDs were reported from 33 states; 3 (1\%) subsequently developed WNND and 91 (22\%) WNF. Of 391 PVDs with complete demographic information available, the median age was 47 years (range, 17-83 years) and 230 (59\%) were male. As in previous epidemics, the majority of PVDs (265 PVDs, 63\%) were reported from 6 states (Arizona, California, Kansas, Louisiana, Nebraska, and Texas; Fig. 4, Table 1), which also accounted for 51 percent (666) of 1,309 WNND cases reported that same year.

\section{TAT investigations}

In 2003, a total of 36 suspected cases of WNV TAT were reported to CDC. Of these, $18(50 \%)$ resulted from public health-initiated investigations and 18 were identified from BCA-initiated investigations. Suspected cases were reported from 15 states: Arizona, California, Colorado, Delaware, Iowa, Illinois, Kansas, Montana, Nebraska, New Hampshire, New Jersey, New Mexico, North Dakota, South Dakota, and Texas.

Of the 36 investigations of suspected TAT, 5 were classified as probable TAT cases and 1 as a confirmed case. Two cases (the confirmed case and one probable case) resulted from BCA-initiated investigations; the other 4 probable cases resulted from public health-initiated investigations. Of the remaining 30 suspected case investigations, no WNV infection was documented in either the donor or the recipient in 12 investigations, and 18 were inconclusive.

In each of the 6 probable or confirmed TAT cases, the recipient received components from multiple donations; however, only 1 blood component containing WNV RNA was found in each case. The 6 infectious donations were collected during July 29 to September 18, 2003; all had been screened in MPs and none were detected. The median age of the 6 recipients was 63 years (range, 13-82 years); 4 had WNV encephalitis, 1 had WNF, and 1 critically ill patient did not have discernible WNVcompatible illness. Seroconversion was documented in 1 case and all donations tested were negative for WNVspecific antibody, indicating that recipient antibody titers were not due to passive transfer via transfusion from seropositive donors. In 4 of these 6 cases, sufficient donation sample was available to estimate the titer of the implicated donor's viremia. The median estimated level of viremia was 0.1 plaque-forming unit (PFU) per $\mathrm{mL}$ (range, 0.06-0.5 PFU/mL; Table 2). Details of the investigations 


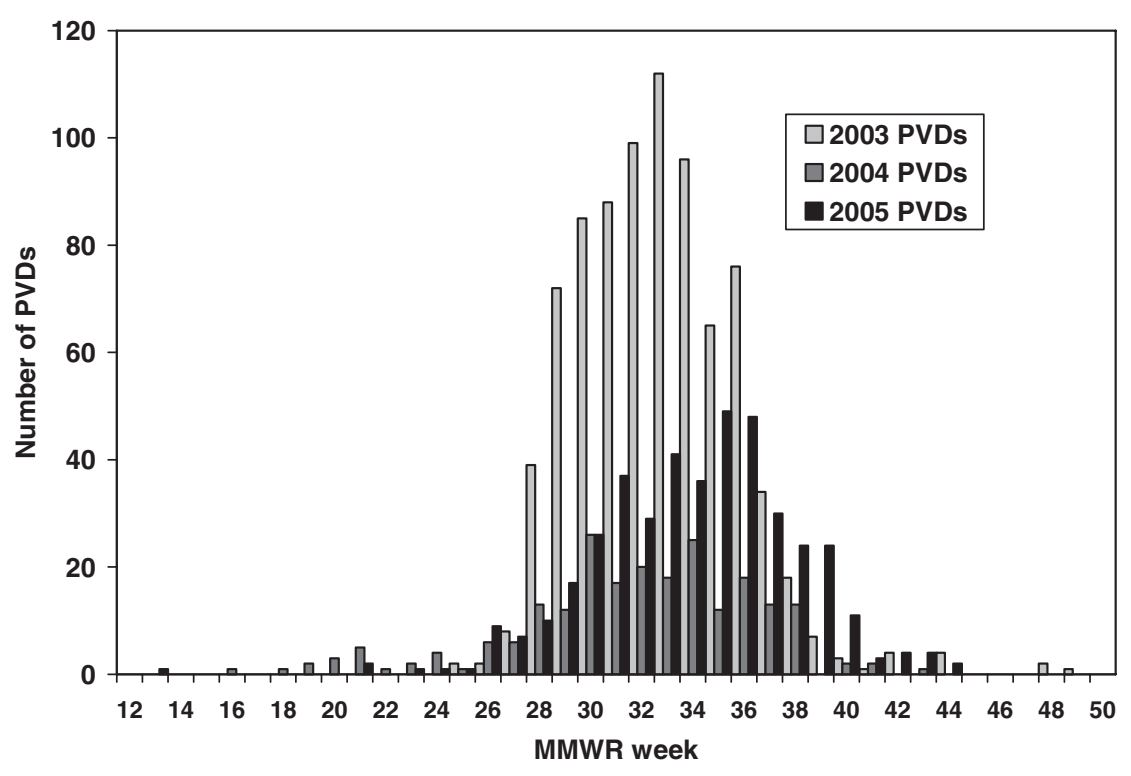

Fig. 2. Reported PVDs by date of donation, United States, 2003 through 2005.

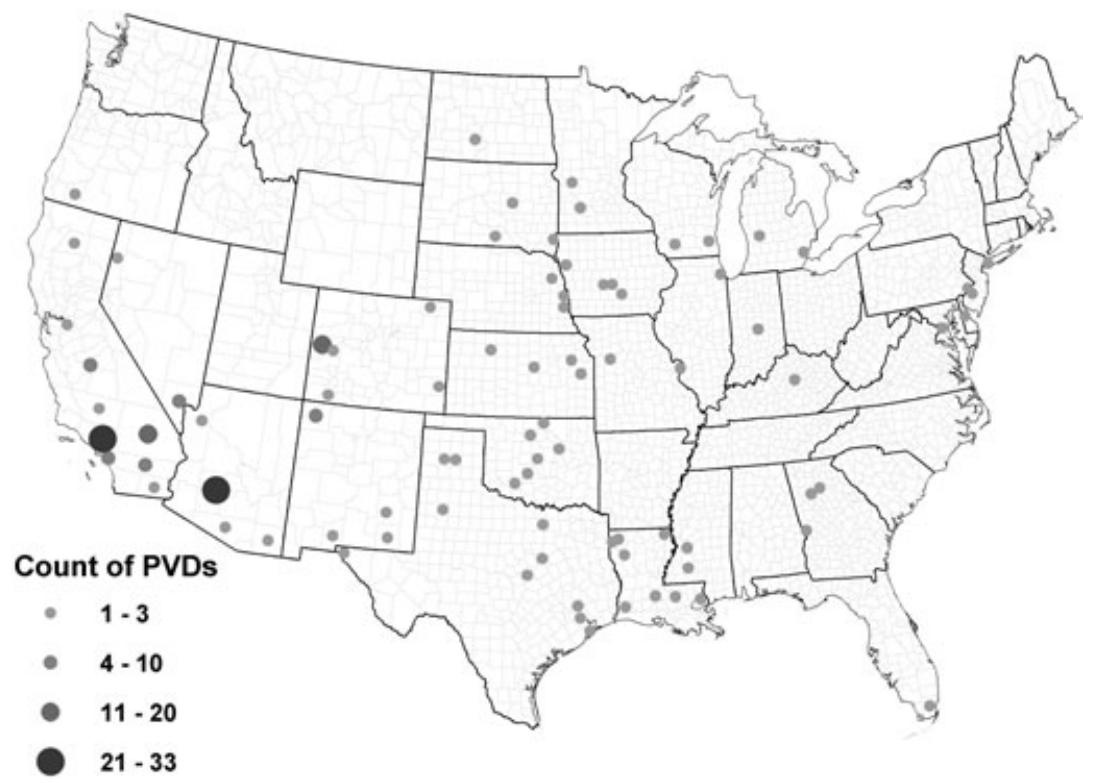

Fig. 3. Number of reported WNV PVDs by county, 2004.

and the clinical courses of 6 confirmed or probable cases are described below.

Patient 1. On August 5, 2003, a 72-year-old man received 5 blood components after aortic graft surgery. All 5 components, derived from separate donations, did not react in MP testing. At the time of transfusion, the patient was in poor health with sepsis. Fever and signs of encephalitis were identified on Day 3 after transfusion. Two more components were transfused on Day 8. On Day 9, as a result of a BCA-initiated investigation, the hospital was notified that the patient had been transfused with a potentially WNV-viremic component in the initial transfusion. WNV infection was confirmed on Day 11 by identifying WNV-specific IgM and neutralizing antibody in the patient's serum. Clinical serum specimens from the patient collected Days 2 and 7 after transfusion were recovered and tested; WNV RNA was detected by rtPCR in both samples but was not present in serum collected on Day 11 after transfusion. The patient improved and was discharged to a longterm care facility.

Samples from the five MP-negative donations were retested individually by NAT. One donation was reactive and was the source of a red blood cell (RBC) unit that was transfused into the WNV-infected recipient. This result was confirmed by repeated testing with different NAT formats. No cocomponents (i.e., plasma, platelets [PLTs]) of the implicated donation were recovered for testing. The index donation sample was negative for WNV-specific IgM and IgG antibodies. The donor was asymptomatic during the preceding month; a blood sample collected 30 days after the implicated donation did not react on NAT but was positive for the presence of WNV-specific IgM and IgG antibody at a commercial laboratory.

Patient 2. On August 6, 2003, an 82year-old woman with myelodysplasia received transfusion of 2 units of RBCs. On Day 11 after transfusion, the patient had onset of nausea, fever, and malaise; on Day 13, she was found unconscious and was admitted to the hospital. During hospitalization, the patient received three additional transfusions. On Day 15, she was discharged to a long-term care facility. Serum collected on the day of discharge was positive for the presence of WNV-specific IgM antibody. Four weeks later (43 days after initial transfusion), she was readmitted to the hospital with a history of repeated falls, septic shock, and gastrointestinal bleeding. The patient expired the following day; the primary cause of death was ascribed to WNV encephalitis.

The 2 units transfused on August 6 were collected from 2 donors on July 30, 2003; both donations did not react in MP testing. Neither donor reported illness before or after the date of donation. Only one donation plasma unit was recovered, which was reactive for WNV RNA by 


\begin{tabular}{|c|c|c|c|c|c|c|c|c|}
\hline Patient & $\begin{array}{c}\text { Age } \\
\text { (years) }\end{array}$ & Sex & $\begin{array}{l}\text { State of } \\
\text { residence }\end{array}$ & $\begin{array}{l}\text { Reason for } \\
\text { transfusions }\end{array}$ & $\begin{array}{c}\text { Number of } \\
\text { components } \\
\text { transfused } \\
\text { during } \\
\text { hospitalization }\end{array}$ & $\begin{array}{c}\text { Type of } \\
\text { components }\end{array}$ & $\begin{array}{l}\text { Estimated } \\
\text { viremia in } \\
\text { implicated } \\
\text { component } \\
(\mathrm{PFU} / \mathrm{mL})\end{array}$ & $\begin{array}{l}\text { WNV illness and TAT } \\
\text { case classification }\end{array}$ \\
\hline$\overline{1}$ & 72 & Male & Texas & CABG* surgery & $7 \dagger$ & RBCsł & NA & Encephalitis; confirmed \\
\hline 2 & 82 & Female & Texas & $\begin{array}{l}\text { Myelodysplastic } \\
\text { syndrome }\end{array}$ & 5 & RBCs & 0.5 & Encephalitis; probable \\
\hline 3 & 13 & Male & lowa & Motor vehicle accident & 3 & RBCs & 0.09 & WNF; probable \\
\hline 4 & 52 & Male & Kansas & $\begin{array}{l}\text { CABG/aortic valve } \\
\text { replacement surgery }\end{array}$ & 7 & RBCs & 0.06 & Encephalitis; probable \\
\hline 5 & 55 & Male & $\begin{array}{l}\text { New Mexico } \\
\text { (hospitalized } \\
\text { in Texas) }\end{array}$ & $\begin{array}{l}\text { Complications of CABG } \\
\text { surgery }\end{array}$ & $154 \S$ & $\begin{array}{l}\text { RBCs, plasma, } \\
\text { PLTs }\end{array}$ & NA & $\begin{array}{l}\text { No discernible WNV } \\
\text { illness; probable }\end{array}$ \\
\hline 6 & 80 & Male & Nebraska & CABG surgery & 26 & $\begin{array}{l}\text { RBCs, plasma, } \\
\text { PLTs }\end{array}$ & 0.11 & Encephalitis; probable \\
\hline \multicolumn{9}{|c|}{$\begin{array}{l}\text { * CABG = coronary artery bypass graft. } \\
\text { † Tested individually in retrospective study. } \\
\text { ₹ } \mathrm{NA}=\text { insufficient specimen available. } \\
\S \text { Not all transfused components were retrospectively tested. A single unit identified on retrospective testing was the basis for the investigation. }\end{array}$} \\
\hline
\end{tabular}

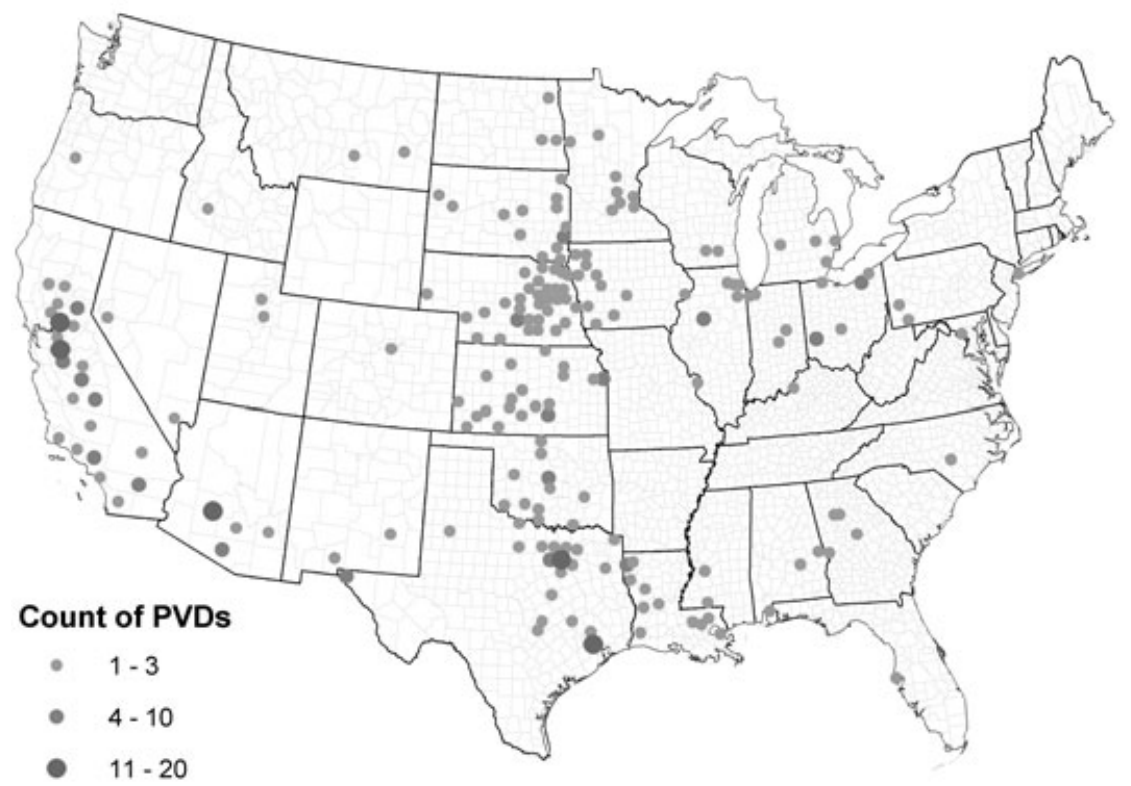

Fig. 4. Number of reported WNV PVDs by county, 2005.

IDT conducted by the BCA. Testing at CDC detected an estimated 0.5 PFU per mL but no WNV-specific IgM antibody. Follow-up serum samples were collected from both donors 10 weeks after donation; only the donor of the implicated unit had WNV-specific IgM and IgG antibody.

Patient 3. On August 31, 2003, a 13-year-old boy was admitted to a hospital with injuries secondary to blunt trauma. On September 1, he received 3 units of RBCs. The recipient was discharged from the hospital on Day 8 after transfusion and developed a maculopapular rash. On Day 11, he was readmitted to the hospital with fever, head- ache, vomiting, and diarrhea. Blood drawn on admission was positive for the presence of WNV-specific IgM antibody. The recipient recovered without sequelae.

The 3 transfused units had been collected during the second week of August 2003. None of the donors reported symptoms of WNV illness before or after donation. All 3 donations did not react in MP testing. All remaining components derived from the donations were recovered. The recovered plasma components were WNV IgMnegative. Recovered plasma from one donor was reactive in IDT. The donor of this unit had developed WNV-specific IgM antibody by Day 50 after the implicated donation.

Patient 4. A 52-year-old man was admitted to a hospital on September 22, 2003, for aortic valve replacement and coronary artery bypass graft surgery. At the time of surgery on September 23, the patient received transfusion of 7 RBC units. He was discharged in stable condition on September 29. On October 7, Day 13 after the last transfusion, the patient was readmitted with fever, confusion, tremors, and hypotension. During this hospitalization, the patient developed mental status changes later attributed to WNV encephalitis based on detected virus-specific IgM in CSF collected on Day 19 after the last transfusion. The patient improved and was discharged to a rehabilitation facility on Hospitalization Day 38.

The 7 transfused RBC units did not react in MP testing. Follow-up serum samples and available cocompo- 
nents from all seven donors were tested; one donor had evidence of recent WNV infection, with WNV-specific IgM and IgG antibody detected in serum collected Day 39 after the date of donation. The implicated donation plasma contained WNV genome but no WNV-specific antibody when tested at CDC.

Patient 5. On August 4, 2003, a 55-year-old man was admitted to a Texas hospital for vascular graft site infection. During 11 weeks of hospitalization, the patient suffered severe complications, requiring multiple surgeries, ventilatory support, and transfusion with 154 blood components. On August 26, the hospital was notified that a RBCs transfused 13 days earlier potentially contained WNV based on IDT done on the associated donation as part of a BCA-initiated retrospective study. No discernible WNV illness in the recipient was detected. A recipient serum sample collected on August 24, Day 11 after transfusion with the implicated component, was positive for the presence of WNV IgM antibodies. No pretransfusion samples were available for testing.

Of the source donations of the 154 components transfused, some donations had been collected before the institution of WNV screening. All of the screened components (the majority of the components given to the patient) did not react by MP testing; less than 10 percent were tested retrospectively by IDT. Low-level WNV RNA was detected in a retrospectively tested donation, collected on August 6. The implicated donor had no reported WNV symptoms at the time of donation. The index donation sample did not have WNV-specific antibodies. The donor's WNV infection was confirmed by detection of IgM and IgG antibody in a follow-up serum sample collected 22 days after the implicated donation was collected.

Patient 6. An 80-year-old man was hospitalized for coronary artery bypass graft surgery. As previously published ${ }^{15}$ after surgery on August 4, 2003, the patient received 26 blood components, including RBCs, PLTs, and fresh-frozen plasma. The patient was discharged on August 14. On August 17, Day 13 after the transfusions, the patient developed mental status changes and fever; he was admitted to the hospital on Day 15 with a diagnosis of encephalitis. Serum and CSF collected on Day 16 after transfusion contained WNV-specific IgM antibody. He improved sufficiently to be discharged to a long-term care facility on September 11.

Of the 26 index donations, 20 did not react in MP testing. Six donations had been collected in February 2003 , before WNV screening had been implemented. Samples from the 20 screened donations were tested by NAT at three different laboratories, including CDC; WNV RNA was detected in one sample by CDC and one of the other two laboratories with an estimated viral load of $0.11 \mathrm{PFU}$ per $\mathrm{mL}$. The plasma from the implicated index donation did not contain WNV-specific IgM antibody. A follow-up serum sample collected from the donor 45 days after the implicated donation was positive for the presence of virus-specific IgM antibody.

\section{4 and 2005 TAT investigations}

In 2004, 15 suspected cases were investigated; 4 of the 15 were BCA-initiated investigations and the remaining 11 were public health-initiated investigations. A single probable case of WNV TAT was documented. The implicated donation, collected on July 17, 2004, in Maricopa County, Arizona, was screened in a nonreactive MP of 16 donation samples. ${ }^{16}$ Of the remaining 14 investigations, no WNV infection was identified in either donor or recipient in 7 investigations and 7 were inconclusive.

Eight suspected cases were investigated during 2005; all were public health-initiated investigations. In 6 investigations, none of the donors were WNV-infected or the recipient did not have an acute WNV infection. Two investigations were inconclusive based on lack of specimens for testing.

\section{DISCUSSION}

Two approaches were implemented in 2003 to reduce the threat of WNV to the US blood supply: 1) deferral of donors with fever and headache in the week before donation and 2) screening donated blood with WNV NAT with an MP testing format. MP format was used because of the constraints of screening the approximately 15 million donations collected annually. Based on a 2003 American Red Cross study, the donor deferral question concerning headache with fever did not predict donor WNV infection status effectively, and the FDA withdrew guidance recommending this deferral question in Fall 2005. ${ }^{17,18}$ Screening by MP-NAT identified 818 infected blood donors who were reported to public health authorities in 2003 and successfully removed at least 1100 potentially infectious components from the blood supply, based on an estimated 1.45 components derived from every donation..$^{19}$ Despite this success, the 6 recipients infected through blood transfusion in 2003 indicated that the risk of acquiring infection from infectious blood components was not completely eliminated by MP-NAT screening.

The NAT assays used in 2003 were developed to detect donations with viral loads comparable to donations implicated in WNV TAT in 2002. In 2003, the estimated viremia levels in implicated donation plasma ranged from 0.06 to $0.50 \mathrm{PFU}$ per $\mathrm{mL}$, lower than the 0.8 to $75.1 \mathrm{PFU}$ per $\mathrm{mL}$ range for TAT cases during 2002. ${ }^{7}$ These levels are estimates based on NAT of small sample volumes of plasma and may overestimate the numbers of infectious virus particles circulating in whole blood or found in separated and processed blood components. Under the investigational new drug process, NAT screening tests were considered experimental, because the performance of the 
assays, including sensitivity and specificity, was undetermined for blood supply screening. For these reasons, the residual risk of transfusion-transmitted WNV infection after screening implementation was not known.

In addition to the sensitivity of the two assays, other limitations may have hindered detection and investigation of possible TAT cases. Public health surveillance for suspect TAT cases and the subsequent investigations were limited by potential lack of recognition of WNV illness in transfusion recipients and by lack of available clinical specimens collected around the time of transfusion, needed to help establish the source of infection. Because clinical specimens are not routinely stored, documenting WNV infection at the time of transfusion was often not possible. Investigations based on BCA retrospective testing studies were similarly limited. Notification of the results of these studies often came weeks after transfusion. Finally, all suspected cases were from states also reporting WNV illnesses, and mosquito transmission may have been the source of infection for recipients in areas with epidemic WNV transmission. Several of the investigated cases, however, were continuously hospitalized before the onset of their WNV infection, which likely reduced or eliminated mosquito exposure.

Data collected during 2003 were carefully considered by the blood industry in collaboration with public health authorities to design strategies to further improve screening sensitivity while considering the impact lower specificity from IDT might have on the US blood supply availability. Strategies to improve sensitivity, such as selective IDT (e.g., triggering of systemwide IDT when at least one viremic donation is collected per week with the standard MP screening algorithm), were employed midseason during 2003 in areas with intense WNV activity and prospectively nationwide starting in $2004 .^{10,11}$ In addition, the manufacturers addressed sensitivity and specificity issues with modifications to both assays. ${ }^{20}$ Year-round IDT may not be feasible; however, switching from pooled to IDT on the basis of BCA-derived triggers may reduce the risk of TAT in areas with intense WNV activity. ${ }^{21}$

Nationally, both 2004 and 2005 epidemics were much smaller than those occurring in 2002 and 2003. At certain times, however, local areas, such as Maricopa County, Arizona, in 2004, may experience intense transmission and have proportionally greater numbers of potentially viremic donations collected, reflecting the effect of local conditions on WNV transmission. The single case of WNV TAT in 2004 involved a donation collected in Maricopa County before the BCA instituted an algorithm for switching to IDT. ${ }^{16}$ Systemwide approaches to WNV screening and blood safety must be flexible enough to respond to the focal and unpredictable nature of WNV epidemics.

The reporting and investigation of suspected TAT cases is critical for the response to known and emerging blood supply risks such as WNV. Screening procedures address known WNV risks, but several characteristics of WNV infection, such as persistence of infectious virus in the presence of antibody response, have not been fully described. ${ }^{22}$ Recently, the FDA published guidance to industry recommending that donors who test viremic or have WNV illness be deferred from donating for 120 days from the date of viremic donation or illness in response to results of BCA follow-up studies of PVDs, which indicate that virus genome can be detected in blood samples collected as many as 104 days after the original viremic donation date. ${ }^{23}$ Blood screening strategies, including the trigger-based IDT screening for WNV, cannot be fully evaluated without the epidemiologic evidence resulting from continuous vigilance for TAT by frontline clinicians and public health authorities. Clinicians should consider possible TAT of infectious disease, including WNV, when evaluating illnesses in recent transfusion recipients and report suspected cases to public health authorities.

\section{ACKNOWLEDGMENTS}

We are grateful to the patients who were the subjects of these investigations and acknowledge the contributions by many members of the blood collection community, especially the generosity of blood donors. The following individuals made important contributions to data collection and specimen tracing and testing during the investigations: Roselyn Hochbein, Olga Kosoy, Amy Lambert, Denize Martin, Amanda Noga, and Sherif Zaki, CDC; Elisabeth Lawaczeck, Arizona Department of Health Services; Babs Johnson, Pima County Health Department; Sarah Brend, Iowa Department of Public Health; Brenda Saldivar and Mary Gilchrist, University of Iowa Hygienic Laboratory, Iowa City, IA; Tom Safranek and Brady Beecham, Nebraska Health and Human Services; Lisa McHugh, New Jersey Department of Health and Senior Services, Hamilton, NJ; Paul Ettestad, New Mexico Department of Health, Santa Fe, NM; Lon Kightlinger, South Dakota Department of Health, Pierre, SD; James Alexander, Tom Betz, Tim Kram, and Jim Schuerman, Texas Department of State Health Services; Anne Denison, City of Amarillo Department of Public Health; Assefa Tulu, Dallas County Health \& Human Services; Tigi Ward, City of Lubbock Health Department; Gary Tegtmeier, Community Blood Center of Greater Kansas City; Ellen Green, Siouxland Community Blood Bank; Tracy Eilderts, The Blood Center of Iowa; Mary Townsend and Deb Anderson, Coffee Memorial Blood Center, Amarillo, TX; William Dickey and Dawn Factor, Belle Bonfils Memorial Blood Center, Denver, CO; Hany Kamel, Blood Systems Inc., Tempe, AZ; Pam Ostboe, Blood Systems Laboratories, Tempe, AZ; Pat Davenport, Carter Blood Care, Bedford, TX; and Jennifer Paolillo, American Red Cross, Gaithersburg, MD. Roy Campbell and Lisa Pealer, CDC, contributed to the investigation design and provided welcome advice. We also thank Allene Carr-Greer, Kay Gregory, and Anita Winters, American Association of Blood Banks, Bethesda, MD, for supporting the national effort to report presumptive viremic blood donors in 2003 and subsequent years. The findings and conclusions in this 
report are those of the authors and do not necessarily represent the views of the Centers for Disease Control and Prevention.

The 2003 WNV transfusion-associated transmission investigation team consisted of

Celso Bianco, MD, America's Blood Centers, Washington, DC

Michael Busch, MD, PhD, Blood Systems Research Institute, San

Francisco, CA

Sally Caglioti, Blood Systems Laboratories, Tempe, AZ

Roger Dodd, PhD, American Red Cross, Rockville, MD

Susan Stramer, PhD, American Red Cross, Gaithersburg, MD

Jay Epstein, MD, Jesse Goodman, MD, MPH, Indira Hewlett, PhD,

Hira Nakhasi, PhD, and Maria Rios, PhD, Center for Biologics

Evaluation and Research, Food and Drug Administration, Rockville, MD

Roland Fahie, Armed Services Blood Program, Falls Church, VA

Louis Katz, MD, America's Blood Centers, Washington DC

Steven Kleinman, MD, American Association of Blood Banks, Bethesda, MD

Lyle Petersen, MD, MPH, Centers for Disease Control and Prevention, Fort Collins, $\mathrm{CO}$

Larry Pietrelli, Roche Molecular Systems, Pleasanton, CA

D. Michael Strong, PhD, Puget Sound Blood Center, Seattle, WA

\section{REFERENCES}

1. Mostashari F, Bunning ML, Kitsutani PT, et al. Epidemic West Nile encephalitis, New York, 1999: results of a household-based seroepidemiological survey. Lancet 2001;358:261-4.

2. Tsai TF, Popovici F, Cernescu C, Campbell GL, Nedelcu NI. West Nile encephalitis epidemic in southeastern Romania. Lancet 1998;352:767-71.

3. Lanciotti RS, Kerst AJ, Nasci RS, et al. Rapid detection of West Nile virus from human clinical specimens, field-collected mosquitoes, and avian samples by a TaqMan reverse transcriptase-PCR assay. J Clin Microbiol 2000;38:4066-71.

4. Southam CM, Moore AE. Induced virus infections in man by the Egypt isolates of West Nile virus. Am J Trop Med Hyg 1954;3:19-50.

5. O'Leary DR, Marfin AA, Montgomery SP, et al. The epidemic of West Nile virus in the United States, 2002. Vector Borne Zoonotic Dis 2004;4:61-70.

6. Hayes EB, Komar N, Nasci RS, et al. Epidemiology and transmission dynamics of West Nile virus disease. Emerg Infect Dis 2005;11:1167-73.

7. Pealer LN, Marfin AA, Petersen LP, et al. Transmission of West Nile virus through blood transfusion in the United States in 2002. N Engl J Med 2003;349:1236-45.

8. Harrington T, Kuehnert MJ, Kamel H, et al. West Nile virus infection transmitted by blood transfusion. Transfusion 2003;43:1018-22.

9. Kleinman S, Glynn SA, Busch M, et al. The 2003 West Nile virus United States epidemic: the America's Blood Centers experience. Transfusion 2005;45:469-79.
10. Stramer SL, Fang CT, Foster BS, et al. West Nile virus among blood donors in the United States, 2003 and 2004. New Engl J Med 2005;353:451-9.

11. Busch MP, Caglioti S, Robertson EF, et al. Screening the blood supply for West Nile virus RNA by nucleic acid amplification testing. N Engl J Med 2005;353:460-7.

12. Procleix WNV assay for investigational use only [5000 test kit]. Package Insert. San Diego: Gen-Probe; 2003.

13. Draft TaqScreen West Nile virus test IUO [48 test kit]. Package Insert. Pleasanton (CA): Roche Diagnostics; 2003 Jul 30.

14. Lindsey HS, Calisher $\mathrm{CH}$, Mathews JH. Serum dilution neutralization test for California group virus identification and serology. J Clin Microbiol 1976;4:503-10.

15. Macedo de Oliveira A, Beecham BD, Montgomery SP, et al. West Nile virus blood transfusion-related infection despite nucleic acid testing. Transfusion 2004;44:1695-9.

16. Centers for Disease Control and Prevention. Transfusionassociated transmission of West Nile virus-Arizona, 2004. MMWR Morb Mortal Wkly Rep 2004;53:842-4.

17. Orton S, Stramer S, Dodd R. Self-reported symptoms associated with West Nile virus infection in RNA-positive blood donors. Transfusion 2005;46:272-7.

18. Guidance for industry: discontinuation of donor deferral related to recent fever with headache as symptom of West Nile virus infection; withdrawal of guidance [monograph on the Internet]. Docket No. 2002D-0467. Rockville (MD): Department of Health and Human Services, Food and Drug Administration; 2005 Jun 30. Available from: http://www. fda.gov/cber/gdlns/wnvdnrdfr.pdf

19. Wallace EL, Churchill WH, Surgenor DM, Cho GS, McGurk S. Collection and transfusion of blood and blood components in the United States, 1994. Transfusion 1998;38:625-36.

20. Busch MP, Tobler LH, Saldanha S, et al. Analytical and clinical sensitivity of West Nile virus RNA screening and supplemental assays available during 2003. Transfusion 2005;45:492-9.

21. Custer B, Busch MP, Marfin AA, Petersen LR. The costeffectiveness of screening the U.S. blood supply for West Nile virus. Ann Intern Med 2005;143:486-92.

22. Centers for Disease Control and Prevention. West Nile virus infections in organ transplant recipients-New York and Pennsylvania, August-September, 2005. MMWR Morb Mortal Wkly Rep 2005;54(dispatch):1-3.

23. Guidance for industry: assessing donor suitability and blood and blood product safety in cases of known or suspected West Nile virus infection [monograph on the Internet]. Rockville (MD): U.S. Food and Drug Administration, Center for Biologics Evaluation and Research (CBER), Food and Drug Administration; 2005 Jun 23. Available from: http:// www.fda.gov/cber/guidelines.htm 